\title{
Assessment of vaccination Coverage and Associated Factors among Children Aged 12-23 Months In Debre Tabor Town, North West Ethiopia, 2019: Community-Based Cross-Sectional Study.
}

Tigabu Desie Emiru ( $\nabla$ tigabud05@gmail.com )

Debre Tabor University https://orcid.org/0000-0001-9535-0190

Debrework Tesgera

University of Gondar

Marye Getnet

University of Gondar

Chalie Marew Tiruneh

Debre Tabor University

Research

Keywords: Complete immunization coverage, Children, Debre Tabor, Ethiopia

Posted Date: March 30th, 2021

DOl: https://doi.org/10.21203/rs.3.rs-347929/v1

License: (a) (1) This work is licensed under a Creative Commons Attribution 4.0 International License.

Read Full License 


\section{Abstract}

\section{Background}

Globally around 2.5 million children under five years of age die every year due to vaccine-preventable diseases. Still, immunization coverage in Ethiopia is low and needs further investigation.

\section{Objective}

The study was aimed to assess complete immunization coverage and associated factors among children aged 12-23 months in Debre Tabor Town, Northwest Ethiopia.

Methods

Community-based cross-sectional study was conducted among children aged 12-23 months from March $1^{\text {st }}$ to March $30^{\text {th }}, 2019$ at Debre Tabor town. A two-stage cluster sampling technique was used to select 824 pairs of mothers to children from the study households. A structured questionnaire was used for data collection. Binary and multivariable logistic regression was fitted to identify the association between dependent and independent variables.

Result

A total of 824 mothers/caretakers were interviewed and almost all of the children took at least a single dose of vaccine. The complete immunization coverage was $80.2 \%$. The odd of complete immunization was; 6 times higher among mothers who gave birth at health facility than at home (AOR 6.29 [95\% Cl: $2.21,17.96]$ ), who had planned pregnancy were 4 times higher than who did not (AOR 4.08 [95\% Cl: 2.20, 7.55]), a home visit by health workers were 3 folds higher (AOR 3.37 [95\% Cl: $2.13,5.33]$ ) and who had good knowledge were 3 times higher than those with poor knowledge (AOR 3.48 [95\% Cl: 2.25, 5.38]).

Conclusion and Recommendation

The prevalence of complete immunization coverage was found to be low among children aged 12-23 months compared to Ethiopia's 2019/20 target which was $95 \%$. Mothers who deliver at the health facility, planned pregnancy, home visits by health workers, and knowledge of mothers on immunization were associated factors. Preventing unplanned pregnancy, promoting institutional delivery, and improving mother's knowledge on child immunization intend to be strengthened.

\section{Background}

Immunization is the mechanism of building a persons' response/resistance to an infectious agent (1). Vaccination coverage is one of the most cost-effective interventions on health that prevent unnecessary suffering from disease, disability, and death (2). There are several serious childhood diseases 
successfully prevented or eradicated by immunization (3). It eradicated small-pox and decreases the occurrences of polio globally by $99 \%$ (4).

Globally, immunization coverage is still low and two million deaths are occurring annually from vaccinepreventable diseases. A study conducted in sub-Saharan African countries shows that the immunization coverage is under $50 \%$ in 2010 (5). The variation and discrepancies within regions and zones remained a challenge and the proportion of zones that achieved DPT3 vaccination coverage at least $80 \%$ was $50 \%$ in 2013 and $73 \%$ in $2014(6)$.

Worldwide approximately 29,000 under-five children die due to vaccine-preventable disease (7). And also around 27 million infants are not vaccinated against common childhood diseases; such as measles or tetanus toxoids. As a result, 2-3 million children will die yearly and many more will fall ill (8).

According to the 2013 world health organization global routine vaccination coverage report; around $70 \%$ of incompletely vaccinated children in the world live in ten countries. Half of these are African countries including Ethiopia (9). Every year around 8 million children in developing countries die before they reach their fifth birthday; many during the first year of life (10).

Most studies in Africa showed that achieving the targeted full immunization coverage is the public health problem of the region $(11,12)$. The overall full immunization coverage was $72.2 \%$ in Senegal, with higher coverage at the capital city which was $86.4 \%$. BCG is the highest $(95.8 \%)$ achievable vaccination in all geographical regions of this study (11). In 2013, Togo has $62 \%$ of fully immunized children with age under-one year; that was improved to $72.3 \%$, in 2017 (12). Burkina Faso had total immunization coverage of $50.2 \%$ in 2009 with $2.52 \%$ having never been vaccinated (4). Based on a study conducted in Nigeria the overall fully immunized was $81.3 \%$ and $16.7 \%$ was partially immunized as well as $2.0 \%$ had never been immunized (13).

In Ethiopia, around one million children were expected to be unvaccinated and about $16 \%$ under-five mortality has been attributed to be vaccine-preventable diseases (14). Monitoring is central to 'A Promise Renewed', a global call to action to end preventable child deaths by 2035 (15).

In Ethiopia, immunization coverage is different in many parts of the country and remains low despite the efforts to improve the services (14). A study conducted in Arba Minch Town and Arba Minch Zuria district, Ambo, and Jigjiga district revealed, only $73.2 \%, 36 \%$, and $36.6 \%$ were fully vaccinated respectively $(14,16$, 17). In a study conducted in Debre Markos town (91.7\%) of children were completely vaccinated (18). In Lay Armachiho District $76.03 \%$ of children were fully immunized (19). In a study conducted in East Gojam Zone full-immunization coverage for the children aged 12-23 months was $58.4 \%$ (20).

According to the Ethiopian demographic health survey (EDHS) 2016, among children age 12-23 months, $39 \%$ were received all basic vaccinations at some time, and only $22 \%$ were vaccinated by their appropriate age. Amhara national regional state was one of the regions with low immunization coverage which is $45.8 \%$ (21). The national target for complete immunization coverage in $2019 / 20$ is $95 \%$ (22). 
Hence, investigating the specific immunization coverage and associated factors must be performed because the EDHS report may not reflect the situation of specific districts, and factors may also vary from district to district. Therefore, this study was tried to fill these gaps by identifying the child immunization coverage and factors associated with full immunization in Debre Tabor town.

Conceptual framework (figure: 1 )

\section{Methods}

\section{Study Area and Period}

The study was conducted in Debre Tabor town; south Gondar Zone, Amhara Regional State, North West Ethiopia. Debre Tabor town is the capital city of South Gondar zone and it is located $98 \mathrm{Kms}$ from Bair Dar $655 \mathrm{~km}$. from the capital city, Addis Ababa to North West direction, and has 6 urban kebeles. The town has a total population of 84,382 ; out of this 19,897 are women in reproductive age (15-49) group and have 36,285 total households. There are 11,429 under-five children in the town among these the estimated children aged12-23 months are 2969. Debre Tabor town has one General hospital, three health centers, and three private clinics and has two health extension workers in each kebele (23). The study was conducted from March 1 ${ }^{\text {st }}, 2019$ to March $30^{\text {th }} 2019$.

\section{Study design and participants characteristics}

A community-Based cross-sectional study design was conducted. All mothers/caretakers to children aged 12-23 months pair in Debre Tabor town was considered as source population and the study population was mothers/caretakers in the selected clusters to children aged 12-23 months pair in Debre Tabor town who fulfilled the inclusion criteria. All mothers/caretakers to children aged 12-23 months pair who were at least reside for six months duration in Debre Tabor town were included. However, mothers/caretakers who were mentally incompetent or critically ill during data collection were excluded from the study.

\section{Sample size determination and sampling procedure}

The sample size was determined by using the single and double population proportion formula. To determine the prevalence of immunization coverage single population proportion formula was used and the following assumptions were made during the calculation. Full immunization coverage of children aged 12-23 months from a study in East Gojam, 2016 report; which was 58.4\% taking as P, 95\% confidence level of certainty, and margin of error $5 \%$. The sample size becomes:-

$$
\mathbf{n}=\frac{(\mathrm{Z} \alpha / 2) 2 \mathrm{p}(1-\mathrm{P})}{\mathrm{d}^{2}}=\frac{(1.96) 2 * 0.584(1-0.584)}{0.05^{2}}=374
$$

Where $\mathbf{n}=$ sample size needed 
$\mathbf{P}=$ Prevalence on complete immunization coverage in East Gojam, 2016 (20)

$\mathbf{Z}=$ significance level at a confidence interval of $95 \%$

$\mathbf{d}=$ margin of error $(0.05)$

$\mathrm{Z} \mathrm{a/2=value} \mathrm{of} \mathrm{the} \mathrm{standard} \mathrm{normal} \mathrm{distribution} \mathrm{corresponding} \mathrm{to} \mathrm{a} \mathrm{significant} \mathrm{level} \mathrm{of} \mathrm{alpha} \mathrm{(a)} 0.05$ which is 1.96 .

By adding 10\% (37) non-responses the final sample size was 412 then since it is clustered sampling by considering 2 as designs effect the final sample size for objective one became 824 . A double population proportion formula was used for significant variables reported in different studies by considering the assumptions of $\mathrm{Cl}$ : $95 \%$, adjusted odds ratio, $80 \%$ power, and the ratio of one to one. After calculating samples for different factors the larger sample size for the study was 824 .

Cluster sampling was used to take the appropriate sample. Then two clusters were selected randomly by lottery method (Figure 2). The first household was selected randomly and the subsequent household was selected according to the principle of the next nearest household. When two or more eligible mothers/caretakers to child pairs were found, only one was included by the lottery method.

\section{Variables of the study}

\section{Dependent Variables}

Complete immunization coverage

\section{Independent Variables}

- The socio-demographic factor of mothers/caretakers: - Religion, ethnicity, age, marital status, educational status, occupation, family size, relation to the child, family living condition.

- Socio-demographic characteristics of the child:- sex, age in month and birth order

- Maternal health care utilization:- planned pregnancy, ANC follow up, number of ANC follow up, TT vaccine and number of TT vaccine, place of birth, PNC follow up and number of PNC follow up

- Health facility-related factors:- availability of vaccines/supplies, distances from the facility, waiting time, health education, and a home visit by health workers

- Knowledge of mother on immunization and vaccine-preventable disease:- immunization as scheduled, the aim of immunization, number of sessions needed to complete, age of child start immunization and age of child complete immunization 


\section{Operational definitions}

- Fully/Complete Immunized/ vaccinated. A child aged 12-23 months who received one dose of Bacillus Calmette-Guerin (BCG), one dose of IPV, one dose of measles, three doses of pentavalent, three doses of PCV, two-dose of Rota, and three doses of OPV

- Partially vaccinated:- A child aged 12-23 months who had missed at least one dose of the seven vaccines(24)

- Not vaccinated:- A child aged 12-23 months who did not receive any vaccine before this study was considered to be not immunized

- vaccinated by card only:-calculated with numerator based only on documented dose, excluding from the numerator those vaccinated by history (16)

- vaccinated by Card plus History: -coverage calculated with numerator based on card and mother's report.

- Knowledge: - seven knowledge questions were asked and correct answers were given a score 1 and incorrect answers score 0 . Those having scored $\geq$ mean (5.51) by categorizing the mothers as having good knowledge those who score less than 5.51 were classified as having poor knowledge (25).

- Caretakers:-Caretaker is the most responsible person that provides care for the child that has no mother due to different reasons (death, separation, or divorce).

- Waiting time: - Waiting time refers to the time a mother spent in the health institution starting from her arrival to obtain child vaccination.

\section{Data collection tool and Techniques}

The interviewer-administered a structured questionnaire which contains knowledge related questions of mother on immunization and vaccine-preventable disease and one checklist for those who had immunization card was used to collect the data. The tool was adapted from published articles $(14,16,18$, $19,24)$ and was translated to Amharic (local language) for easy understanding and translated back to English for analysis. The questionnaire has forty-eight questions with five parts consists of both closedended and open-ended and one checklist. The data collectors have completed the necessary information based on participant responses. Four diploma nurses participated in data collection and two BSc nurses supervised the data collection.

\section{Data quality control}

Data collectors were trained for one day about objectives, procedures, and the content of questionnaires and interview techniques before they go to data collection. The pretest was performed at Kimir Dingay town on $5 \%$ (41) of sample size and the necessary modification was made before actual data collection. 
During the actual data collection, any confusing or inconsistent questions were checked daily. Epi info 7.2.0.1 was used for data entry to reduce errors during data entry.

\section{Data processing and analysis}

The data was coded, cleaned, and entered into Epi info version 7.2.0.1 and then, the data was exported to SPSS window version 20 for analysis. Descriptive statistics, frequency, and proportion were computed.

The association between each independent variable and the outcome variable was assessed by using binary logistic regression. All variables with $P \leq 0.2$ in the bivariate analysis were further taken to multivariable analysis to control all possible confounders. Adjusted odds ratio along with $95 \% \mathrm{Cl}$ was and P-value $<0.05$ was considered to declare factors that have a statistically significant association with complete immunization

\section{Ethical Consideration}

Ethical clearance was obtained from the School of Nursing Ethical review committee on the behalf of University of Gondar review board. The verbal informed consent was acceptable and approved by the Ethical review board on the behalf of University of Gondar, and that this study was conducted under the declaration of Helsinki. A formal letter of cooperation was written to zonal health department and town administrator of South Gondar zone from University of Gondar and permission was obtained from respective kebeles administrators. All the study participants were informed about the purpose and procedure of the study and their right to refuse was respected and verbal consent was obtained from all study participants before the interview. The respondents were also told that the information obtained from them was treated with complete confidentiality and do not cause any harm to them. The families of children who were found partially immunized or not immunized at all during the data collection period were advised and linked to health extension workers and health centers.

\section{Results}

\section{Socio-demographic characteristics of mothers/caretakers}

Data of 824 pairs of mothers and children aged 12-23 months old were analyzed and the response rate was 100\%. Among the participant, 501 (60.8\%), were in age groups between 26 and 35 years with a mean age of 29.1 and standard deviation (S.D) \pm 5.25 years. Majority of the respondents were Amhara 808 $(98.1 \%)$ and $86.5 \%$ were Orthodox Christian. About $83.7 \%$ of the respondents were married. Family size for $71.2 \%$ of respondents was $\leq 4$. One hundred seven $(13.0 \%)$ of the mothers were not educated. Regarding occupational status, about one third (36.4\%) were housewives. Almost all respondents 823 (99.9) were biological parents of the child and $95.5 \%$ of the children, both parents were alive. (Table 1) 
Four hundred twenty-eight (51.9\%) of children were males and the mean age of the children was 17.88 months with S.D \pm 3.7. About 796 (96.6\%) were delivered at the health facility and $392(47.6 \%)$ of the children were first-order birth. (Table 2)

\section{Maternal health care utilization}

Of all study participants, 751 (91.1\%) of the index child pregnancy were planned 817 (99.2) had ANC follow during their index child pregnancy, and 674 (82.5\%) had $\geq$ four visits. Eight hundred thirteen $(98.7 \%)$ of mothers were vaccinated for tetanus toxoid among whom 48 (5.9\%) had one dose. Three hundred twenty (38.8\%) had PNC follow up and most of $(71.0 \%)$ them had less than or equal to two visits. (Table 3 )

\section{Children's complete immunization/ vaccination coverage}

Almost all of the children 823 (99.9\%) were immunized at least one dose of vaccines and only one participant was not immunized at all.

Complete immunization coverage in this study was 661 (80.2\%) by card plus by mothers report; from those 369 (44.8\%) were completely immunized by card only and $162(19.7 \%)$ were partially immunized. In this study the coverage of each individual vaccine was BCG $95.7 \%$, OPV3 $90.7 \%$, pentavalent and PCV3 $90.5 \%$, Rota2 vaccine $97.1 \%$, IPV $89.8 \%$ and measles $87.7 \%$ (Table 4). More than half of $(52.9 \%$ ) the participant had an immunization card of their children. Among those who had immunization cards, complete immunization coverage was $84.6 \%$.

\section{Mothers' Knowledge on vaccination}

All of the respondents were heard about immunization and $88 \%$ percent of them heard from health professionals. Most of the respondents 736 (89.3\%), knew that the purpose of immunization of the children was to prevent disease. Five hundred forty-four (66.0\%) of the mothers knew when that immunization starts just after birth. Regarding sessions needed to get full immunization 455 (55.2\%) answered five sessions and 797 (96.7\%), they responded that children's immunization is completed at the age of nine months. Based on the mean score of correctly answered knowledge questions $54.5 \%$ of mothers had good knowledge (Table 5). Based on the mean value $54.5 \%$ of mothers had good knowledge.

\section{Delivery at Health institution and related findings}

About $386(46.8 \%)$ of the respondents were distance from the health institute between 30-60 minutes and regarding waiting time at the immunization site 399 (48.4\%) of the respondents between 15-30 minutes. 
Seven hundred thirty seven (89.4\%) of the respondents were got health education at health facilities, $80.6 \%$ had home visit by health workers and almost all said the health facility had readiness for immunization service (Table 6).

\section{Reasons for not fully vaccinated}

For those children who were not fully vaccinated (163), the mothers/caretakers responded to different reasons for not completing their vaccination and respondents had multiple responses. Fifty eight (35.6\%) of the mothers reported being busy with other tasks, $46(22.2 \%)$ of them stated vaccines can be given in the future regardless of the usual schedule, $31(19.0 \%)$ child was sick, $22(13.5 \%)$ fear of side effects, 27 (16.6\%) no vaccine at the health facility, $18(11.0 \%)$ do not know schedule and place and only $3(0.02 \%)$ due to distance of health facility.

\section{Factors Associated with Complete vaccination status of children}

To determine factors associated with child complete vaccination status binary logistic regression analysis was used. On bivariate analysis; marital status of the mother, maternal occupation, educational status of mothers, birth order of the index child, place of birth for index child, ANC follow up, PNC follow up, mother vaccinated for tetanus toxoid, planned pregnancy, health education at the health institution, home visit by health workers and knowledge of mothers on immunization were found to be significantly associated with full immunization.

In a multivariable logistic analysis by place of birth for index child with AOR: 6.29 (95\% Cl: 2.21, $17.96 \mathrm{Cl}$ ), planned pregnancy AOR: 4.08 (95\% Cl: 2.20, $7.55 \mathrm{Cl})$, home visit by health workers AOR: 3.37 (95\% Cl: $2.13,5.33 \mathrm{Cl})$ and knowledge of mothers on immunization AOR: $3.48(95 \% \mathrm{Cl}: 2.25,5.38 \mathrm{Cl})$ were remained significantly associated with the outcome variable with $95 \% \mathrm{Cl}$ and P-value of $\leq 0.05$. (Table 7)

\section{Discussion}

This study tried to assess complete vaccination coverage and associated factors among children aged between 12 and 23 months living in Debre Tabor town. Complete vaccination coverage status of children was confirmed using immunization cards of children and mothers recall method.

The study found that complete vaccination coverage in the study area was $80.2 \%$ with $(95 \% \mathrm{Cl}$ : [77.5, $83.0 \%]$ ). This finding was in line with a study conducted in Tehulederie District (83\%) fully immunized (26) and a study conducted in Nigeria the overall fully vaccinated was $81.3 \%$ (13).

The current finding is higher than studies on complete immunization coverage in the country; Arba Minch town and Zuria District (73.2\%), Ambo Woreda (35.4\%), Mizan Aman Town (42.2\%), North Gondar (76\%) $(14,17,19,24)$, and EDHS (2016) (39\%) (21) complete immunization coverage was higher. The 
discrepancy might due to increasing access to vaccination and community awareness from time to time and also EDHS report has used sample data from different regions that include remote areas where access to health care is difficult to reach. However, this study was much lower than the study done in Debre Markos town (91.7\%) (18). The difference might be explained by this study includes inactivated polio vaccine (IPV) as one of the vaccines to say a child completely immunized that may cause for the differences but not in the study of Debre Markos.

In this study the coverage of each vaccine was BCG 95.7\%, OPV3 $90.7 \%$, pentavalent and PCV3 $90.5 \%$, Rota2 vaccine 97.1 , and measles $87.7 \%$. BCG may due to most of the respondents were delivered at the health institution as well it could be given at any time starting from birth. According to the expanded program of immunization schedules of Ethiopia, OPV, PCV, and pentavalent vaccines are being given with a similar schedule, and the coverage of this vaccine was slightly similar. But the coverage of measles lower than the other vaccines may be due to the relatively long interval between the third dose of pentavalent and measles, a number of children may not return. This finding is higher than the study conducted in Arba Minch town and Zuria District (17). The discrepancy might due to increasing access to vaccination and community awareness from time to time.

This study showed that there is a decline in coverage of immunization from BCG (95.7\%) at birth to measles $(87.70 \%)$ and the proportion of fully immunized children $(80.2 \%)$ which indicated that there was a significant proportion of defaulting children.

In this study place of birth for index child was a significant contributor for complete immunization status. Complete immunization was 6.29 folds in children who had born at the health facility $[(95 \% \mathrm{Cl}=2.21$, 17.96)] than being born at home. This result is consistent with a study done in different parts of Ethiopia; Mizan Aman Town AOR 2.4 [95\% Cl: $(1.38,3.67)$ ], Ambo woreda (AOR = 2.1, 95\% Cl: 1.3-3.4), Arba Minch town and Zuria District $[\mathrm{AOR}(95 \% \mathrm{Cl})=0.47(0.26,0.85)]$ and Jigjiga district $(\mathrm{AOR}=2.02,95 \% \mathrm{Cl}=1.24$, 3.28) $(14,16,17,24)$. In another study conducted in Machakel Woreda shows that being delivered at home is a significant factor for incomplete immunization [AOR=4.113, (95\% Cl: 2.263, 7.475)] (28). The reason might be first-that BCG and OPVO immunization starts just after delivery and creates a link for consecutive immunization schedule, secondly counseling on neonatal care and client education on benefits of immunization given in early postpartum period.

Planned pregnancy was another factor found significant for complete immunization. The odds of complete immunization was 4 times higher in planned pregnancy than those who had unplanned pregnancy AOR: 4.08 (95\% Cl: 2.20,7.55). This is consistent with the reports from Debre Markos town with AOR: 2.89 (95\% Cl: $(1.17,7.17))(18)$. This might be due to mothers who had planned pregnancy gave more attention to immunize their children prior to their daily activity and might have proper health care service utilization during and after pregnancy. In contrast to this finding unplanned pregnancy was not the factor for child complete immunization in many studies in Ethiopia which analyzed as a systematic review, and meta-analysis of cross-sectional studies immunization coverage and its determinant factors and another study on childhood vaccination in rural southwestern Ethiopia $(29,30)$. 
This is the new insight for the health sectors (concerned body on Ethiopia children health) on immunization that indicates immunization services should assimilate with family planning service in the actual service delivery setups that make it convenient for mothers and their children to receive vaccinations at primary healthcare settings in Ethiopia everywhere any time.

The odds of complete immunization was three folds in mothers who had home visits by health workers AOR: $3.37(95 \% \mathrm{Cl}: 2.13,5.33)$ than those who had no home visits by health workers. This is consistent with the study reports from JigJiga $(A O R=1.92,95 \% \mathrm{Cl}=1.17,3.16)(16)$. This may be home visits may help mothers/caretakers to get awareness on the immunization importance and reminders on schedules.

The odds of complete immunization was three times higher in mothers with good knowledge compared to mothers with poor knowledge AOR $3.48(95 \% \mathrm{Cl} ; 2.25,5.38)$ this is consistent with the previous studies done in Ethiopia; Mecha district, Arbagona District, and Sodo Zurea (31-33). This might be due to mothers having good knowledge of complete immunization gave more attention to immunize their children.

\section{Strength and Limitation of the study}

Strength: - This study has used relatively larger sample size form most of the other studies in the country

Limitation: - Immunization coverage might have been under-reported or over-reported by mothers/caretakers because mothers might not remember all the number of doses that the child took.

\section{Conclusion}

In this study even though the proportion of complete immunization coverage higher than most of the findings in the country and EDHS data; it was found to be low among children aged 12-23 months compared to the national target (Health Sector Transformation Plan 2015/16 - 2019/20) that at least the full/complete immunization coverage must be $95 \%$. Mothers who deliver at health facility, planned pregnancy, home visit by health workers and knowledge of mother towards immunization were factors associated with full immunization status of children. Lastly, understanding the coverage of immunization and its contributing factor helps to improve its status in the country. Also, it helps policymakers and health managers to integrate maternal health care services and their children's immunization service to accomplish complete immunization coverage.

\section{RECOMMENDATIONS}

\section{To policymakers and health managers}

Policymakers and health managers better to integrate maternal health care services, family planning services, and their children immunization service to accomplish complete immunization coverage 


\section{To south Gondar zonal health department and Debre Tabor town health office}

Better to plan on improving maternal health care service utilization and shall give special attention to improving awareness of the community towards child immunization (importance/purpose, schedule/sessions to complete immunization) and shall give direction for health professionals to have regular home visits. In collaboration with, mass media, HEW and other health professionals to disseminate messages should rigorously aware the mothers and health educations about complete immunization coverage; to improve the knowledge of mothers

\section{To health professionals/ HEWs}

Be going to promote institutional delivery for those mothers' who attend ANC and use the opportunity to provide awareness for mothers on vaccine side effects, schedules, and purposes. Regular home visits to improve complete immunizations by reminding the sessions, work on family planning, and encourage mothers to use maternal health care services like family planning.

\section{Abbreviations}

ANC: Antenatal Care, AOR: Adjusted Odds Ratio, BCG: Bacille Calmette Guerin, DPT: Diphtheria Pertusis Tetanus, EDHS: Ethiopian Demographic and Health Survey, EPI: Expanded Program on Immunization, HEW: Health extension worker, HSTP: Health Sector Transformation Plan, HW: Health Worker, MDG: Millennium Development Goal, OR: Odds Ratio, PCV: Pneumococcal Conjugated Vaccine, SDGs: Sustainable Development Goals, SPSS: Statistical Package for Social Sciences, UNICEF: United Nation Children's Fund, UoG: University of Gondar, WHO: World Health Organizations

\section{Declarations}

Ethical approval and consent to participate. Ethical clearance was obtained from School of Nursing Ethical review committee on the behalf of University of Gondar. The verbal informed consent was acceptable and approved by the Ethical review board on the behalf of University of Gondar, and that this study was conducted under the declaration of Helsinki. A formal letter of cooperation was written to zonal health department and town administrator of South Gondar zone from University of Gondar and permission was obtained from respective kebeles administrators. Study participants were informed about the purpose and procedure of the study and their right to refuse was respected and verbal consent was obtained from all study participants prior to the interview.

Consent to publication. Not applicable

Availability of data and materials. Data will be available upon request from the corresponding author.

Competing interests. The authors declare that they have no competing interests. 
Funding. This research didn't receive any grant from any funding agency in the public, commercial, or notfor-profit sectors.

Authors' Contribution: All authors made a significant contribution to the work reported, whether that is in the conception, study design, execution, acquisition of data, analysis and interpretation, or in all these areas; took part in drafting, revising or critically reviewing the article; gave final approval of the version to be published; have agreed on the journal to which the article has been submitted; and agree to be accountable for all aspects of the work.

Acknowledgment: The author acknowledged co-authors, data collectors, and supervisors. The author is also deeply acknowledging Debre Tabor University. Last but not least, the respondents deserve sincere thanks for their kind responses

\section{References}

1. WHO. GIVS: global immunization vision and strategy: 2006-2015. Geneva: World Health Organization, 2005.

2. India Go. Multi Year Strategic Plan 2013 - 17 Universal Immunization Program; REACHING EVERY CHILD. Department of Health and Family Welfare, Ministry of Health and Family Welfare.

3. Gentile A, Bhutta Z, Bravo L, Samy AG, Garcia RDJ, Hoosen A, et al. Pediatric disease burden and vaccination recommendations: understanding local differences. International Journal of Infectious Diseases. 2010;14(8):e649-e58.

4. Sanou A, Simboro S, Kouyaté B, Dugas M, Graham J, Bibeau G. Assessment of factors associated with complete immunization coverage in children aged 12-23 months: a cross-sectional study in Nouna district, Burkina Faso. BMC international health and human rights. 2009;9(1):S10.

5. Machingaidze S, Wiysonge CS, Hussey GD. Strengthening the expanded programme on immunization in Africa: looking beyond 2015. PLoS medicine. 2013;10(3):e1001405.

6. LaFond, A.K., \& Sequeira, J.M.(2012). Drivers of Routine Immunization System Performance at the District Level: Ethiopia Case Study, ARISE Research Brief No. 2. Arlington, VA: JSI Research \& Training Institute, Inc., ARISE Project for the Bill \& Melinda Gates Foundation.

7. Tadesse H, Deribew A, Woldie M. Predictors of defaulting from completion of child immunization in south Ethiopia, May 2008-A case control study. BMC public health. 2009;9(1):150.

8. Burton A, Monasch R, Lautenbach B, Gacic-Dobo M, Neill M, Karimov R, et al. WHO and UNICEF estimates of national infant immunization coverage: methods and processes. Bulletin of the World Health Organization. 2009;87:535-41.

9. Harris JB, Gacic-Dobo M, Eggers R, Brown DW, Sodha SV. Global routine vaccination coverage, 2013. MMWR Morbidity and mortality weekly report. 2014;63(46):1055-8.

10. Kamadjeu R. The future of routine immunization in Africa. The Pan African medical journal. 2017;27(Suppl 3):1. 
11. Mbengue MAS, Mboup A, Ly ID, Faye A, Camara FBN, Thiam M, et al. Vaccination coverage and immunization timeliness among children aged 12-23 months in Senegal: a Kaplan-Meier and Cox regression analysis approach. The Pan African medical journal. 2017;27(Suppl 3):8.

12. Ekouevi DK, Gbeasor-Komlanvi FA, Yaya I, Zida-Compaore WI, Boko A, Sewu E, et al. Incomplete immunization among children aged 12-23 months in Togo: a multilevel analysis of individual and contextual factors. BMC public health. 2018;18(1):952.

13. Adebiyi OA, Ilesanmi OS, Ajumobi O, Jama A, Ali M, Lindstrand A, et al. Perspectives on the Measles, Mumps and Rubella Vaccination among Somali Mothers in Stockholm. PloS one. 2018;15(11).

14. Etana B, Deressa W. Factors associated with complete immunization coverage in children aged 1223 months in Ambo Woreda, Central Ethiopia. BMC public health. 2012;12(1):566.

15. UNICEF. The Millennium Development Goals Report United Nations, New York, June 2013-10 000.

16. Mohamud AN, Feleke A, Worku W, Kifle M, Sharma HR. Immunization coverage of 12-23 months old children and associated factors in Jigjiga District, Somali National Regional State, Ethiopia. BMC public health. 2014;14(1):865.

17. Animaw W, Taye W, Merdekios B, Tilahun M, Ayele G. Expanded program of immunization coverage and associated factors among children age 12-23 months in Arba Minch town and Zuria District, Southern Ethiopia, 2013. BMC public health. 2014;14(1):464.

18. Gualu T, Dilie A. Vaccination Coverage and Associated Factors among Children Aged 12-23 Months in Debre Markos Town, Amhara Regional State, Ethiopia. Advances in Public Health. 2017;2017.

19. Kassahun MB, Biks GA, Teferra AS. Level of immunization coverage and associated factors among children aged 12-23 months in Lay Armachiho District, North Gondar Zone, Northwest Ethiopia: a community based cross sectional study. BMC research notes. 2015;8(1):239.

20. Tadesse Dagget Tesfaye WATASK. Vaccination coverage and associated factors among children aged 12 - 23 months in Northwest Ethiopia Human Vaccines \& Immunotherapeutics. 2016.

21. EDHS. Central Statistical Agency (CSA) [Ethiopia] and ICF. 2016. Ethiopia Demographic and Health Survey 2016. Addis Ababa, Ethiopia, and Rockville, Maryland, USA: CSA and ICF. 2016.

22. FMoH. Health Sector Transformation Plan. . Ethiopian. October 2015.

23. Ayaliew T. Estie Woreda Health Office population estimation report and $\mathrm{CBH}$ coordinating office unpublished. 2020.

24. Meleko A, Geremew M, Birhanu F. Assessment of Child Immunization Coverage and Associated Factors with Full Vaccination among Children Aged 12-23 Months at Mizan Aman Town, Bench Maji Zone, Southwest Ethiopia. International journal of pediatrics. 2017;2017.

25. Asfaw AG, Koye DN, Demssie AF, Zeleke EG, Gelaw YA. Determinants of default to fully completion of immunization among children aged 12 to 23 months in south Ethiopia: unmatched case-control study. The Pan African medical journal. 2016;23:100.

26. Ebrahim TY, Salgedo WB. Childhood immunization coverage in Tehulederie district, Northeast of Ethiopia: A community based cross sectional study. International Journal of Current Research. 
2015;7(9):20234-40.

27. Pavlopoulou ID, Michail KA, Samoli E, Tsiftis G, Tsoumakas K. Immunization coverage and predictive factors for complete and age-appropriate vaccination among preschoolers in Athens, Greece: a cross-sectional study. BMC public health. 2013;13(1):908.

28. Yenit M, Assegid S, Abrha H. Factors Associated With Incomplete Childhood Vaccination among Children 12-23 Months of Age in Machakel Woreda, East Gojjam Zone: ACase-controlStudy. Journal of Pregnancy and Child Health. 2015;2(4):180.

29. Eshete A, Shewasinad S, Hailemeskel S. Immunization coverage and its determinant factors among children aged 12-23 months in Ethiopia: a systematic review, and Meta-analysis of cross-sectional studies. BMC pediatrics. 2020;20(1):1-13.

30. Wado YD, Afework MF, Hindin MJ. Childhood vaccination in rural southwestern Ethiopia: the nexus with demographic factors and women's autonomy. The Pan African medical journal. 2014;17(Suppl 1).

31. Legesse E, Dechasa W. An assessment of child immunization coverage and its determinants in Sinana District, Southeast Ethiopia. BMC pediatrics. 2015;15(1):31.

32. Asfaw AG, Koye DN, Demssie AF, Zeleke EG, Gelaw YA. Determinants of default to fully completion of immunization among children aged 12 to 23 months in south Ethiopia: unmatched case-control study. Pan African Medical Journal. 2016;23(1).

33. Debie A, Taye B. Assessment of fully vaccination coverage and associated factors among children aged 12-23 months in Mecha District, North West Ethiopia: A cross-sectional study. Sci J Public Health. 2014;2(4):342-8.

\section{Tables}

Table 1: Socio-demographic characteristics of mothers/caretakers in Debre Tabor town, North West Ethiopia, $2019(n=824)$. 


\begin{tabular}{|c|c|c|c|}
\hline Variables & Category & Frequency & $\begin{array}{l}\text { Percent } \\
\text { (\%) }\end{array}$ \\
\hline \multirow[t]{3}{*}{ Age of mothers } & $18-25$ & 227 & 27.5 \\
\hline & $26-35$ & 501 & 60.8 \\
\hline & $36-45$ & 96 & 11.7 \\
\hline \multirow[t]{4}{*}{ Ethnicity } & Amhara & 808 & 98.1 \\
\hline & Oromo & 9 & 1.1 \\
\hline & Tigre & 5 & 0.6 \\
\hline & Others & 2 & 0.2 \\
\hline \multirow[t]{4}{*}{ Marital status } & Married & 690 & 83.7 \\
\hline & Divorced & 83 & 10.1 \\
\hline & Widowed & 36 & 4.4 \\
\hline & Unmarried & 15 & 1.8 \\
\hline \multirow[t]{4}{*}{ Religion } & Orthodox & 713 & 86.13 \\
\hline & Muslim & 82 & 10 \\
\hline & Protestant & 22 & 2.7 \\
\hline & Catholic & 7 & 0.8 \\
\hline \multirow[t]{6}{*}{ Occupational status } & Housewife & 300 & 36.4 \\
\hline & Merchant & 218 & 26.5 \\
\hline & Government employee & 262 & 31.8 \\
\hline & Daily Worker & 28 & 3.4 \\
\hline & $\begin{array}{l}\text { Non-governmental } \\
\text { organization }\end{array}$ & 8 & 1.0 \\
\hline & Other (student) & 8 & 1.0 \\
\hline \multirow[t]{4}{*}{ Educational status of the mother } & No education & 107 & 13.0 \\
\hline & Primary education & 118 & 14.3 \\
\hline & Secondary education & 258 & 31.3 \\
\hline & More than secondary & 341 & 41.4 \\
\hline \multirow{2}{*}{$\begin{array}{l}\text { Numbers of the family live in the } \\
\text { household }\end{array}$} & $\leq 4$ & 587 & 71.2 \\
\hline & $\geqq 5$ & 237 & 28.8 \\
\hline
\end{tabular}




\begin{tabular}{|llll|}
\hline Family living conditions & Both are alive & 787 & 95.5 \\
\hline mother only & 36 & 4.4 \\
\hline father only & 1 & 0.1 \\
\hline
\end{tabular}

Table 2: Socio-demographic characteristics of children aged 12-23 months in Debre Tabor town, North West Ethiopia, 2019 ( $n=824)$.

\begin{tabular}{|c|c|c|c|}
\hline Variables & Category & Frequency & Percent (\%) \\
\hline \multirow[t]{2}{*}{ Sex of the child } & Male & 428 & 51.9 \\
\hline & Female & 396 & 48.1 \\
\hline \multirow[t]{3}{*}{ Age of the child } & $12-15$ & 267 & 32.4 \\
\hline & $16-19$ & 244 & 29.6 \\
\hline & $20-23$ & 313 & 38.0 \\
\hline \multirow[t]{4}{*}{ Birth order of the child } & First & 392 & 47.6 \\
\hline & Second & 259 & 31.4 \\
\hline & Third & 122 & 14.8 \\
\hline & Fourth and above & 51 & 6.2 \\
\hline \multirow[t]{2}{*}{ Places of birth } & Health Institute & 796 & 96.6 \\
\hline & Home & 28 & 3.4 \\
\hline
\end{tabular}

Table 3: History of maternal health care utilization in Debre Tabour town, North West Ethiopia, 2019 ( $n=$ 824). 


\begin{tabular}{|llll|}
\hline Variables & Category & Frequency & $\begin{array}{c}\text { Percent } \\
(\%)\end{array}$ \\
\hline Was your pregnancy planned? & Yes & 751 & 91.1 \\
\cline { 2 - 4 } & No & 73 & 8.9 \\
\hline $\begin{array}{l}\text { Did you attend antenatal care follow up during your } \\
\text { pregnancy? }\end{array}$ & Yes & 817 & 99.2 \\
\hline How many visits you have(n=817) & No & 7 & 0.8 \\
\hline Are you vaccinated for tetanus toxoid vaccine? & $\leq 2$ & 35 & 4.3 \\
\hline How many doses you have(n=813) & 3 & 108 & 13.2 \\
\hline Did you have postnatal care follow up? & $\geq 4$ & 674 & 82.5 \\
\hline How many visits you have(n=320) & Yes & 813 & 98.7 \\
\hline & No & 11 & 1.3 \\
\hline & One & 48 & 5.9 \\
\hline & Two & 337 & 41.5 \\
\hline
\end{tabular}

Table 4: vaccination coverage of children aged 12-23 months based on mothers report and by immunization card for each vaccine schedule, Debre Tabor town, North West Ethiopia, $2019(n=824)$ 


\begin{tabular}{|c|c|c|c|}
\hline Variables/categories & & frequency & Percent (\%) \\
\hline \multirow[t]{2}{*}{ Had the child taken any vaccination? } & Yes & 823 & 99.9 \\
\hline & No & 1 & 0.1 \\
\hline \multirow[t]{2}{*}{ Do you have an immunization card of your child? } & Yes & 436 & 52.9 \\
\hline & No & 388 & 47.1 \\
\hline \multirow[t]{4}{*}{ Was your child took all vaccines? } & Yes & 661 & 80.2 \\
\hline & No & 163 & 19.8 \\
\hline & Yes & 789 & 95.7 \\
\hline & No & 35 & 4.3 \\
\hline \multirow[t]{2}{*}{ OPV 1} & Yes & 822 & 99.8 \\
\hline & No & 2 & 0.2 \\
\hline \multirow[t]{2}{*}{ OPV2 } & Yes & 814 & 98.7 \\
\hline & No & 10 & 1.3 \\
\hline \multirow[t]{2}{*}{ OPV3 } & Yes & 747 & 90.7 \\
\hline & No & 77 & 9.3 \\
\hline \multirow[t]{2}{*}{ DTP-HepB1-Hib1 and PCV1 } & Yes & 823 & 99.9 \\
\hline & No & 1 & 0.1 \\
\hline \multirow[t]{2}{*}{ DTP-HepB2-Hib2 and PCV2 } & Yes & 814 & 98.8 \\
\hline & No & 10 & 1.2 \\
\hline \multirow[t]{2}{*}{ DTP-HepB3-Hib3 and PCV3 } & Yes & 746 & 90.5 \\
\hline & No & 78 & 9.5 \\
\hline \multirow[t]{2}{*}{ IPV } & Yes & 740 & 89.8 \\
\hline & No & 84 & 10.2 \\
\hline \multirow[t]{2}{*}{ Rota1 } & Yes & 820 & 99.5 \\
\hline & No & 4 & 0.5 \\
\hline \multirow[t]{2}{*}{ Rota 2} & Yes & 800 & 97.1 \\
\hline & No & 24 & 2.9 \\
\hline \multirow[t]{2}{*}{ Measles } & Yes & 718 & 87.7 \\
\hline & No & 106 & 12.3 \\
\hline
\end{tabular}




\begin{tabular}{|llll|} 
Completely vaccinated by card only & Yes & 369 & 44.8 \\
\hline No & 455 & 55.2 \\
\hline
\end{tabular}

Table 5 Respondents knowledge on vaccination and vaccine-preventable diseases in Debre Tabor town, North West Ethiopia, $2019(n=824)$ 


\begin{tabular}{|c|c|c|c|}
\hline Variables & Category & Frequency & $\begin{array}{l}\text { Percent } \\
(\%)\end{array}$ \\
\hline Heard about immunization & Yes & 824 & 100 \\
\hline \multirow{4}{*}{$\begin{array}{l}\text { Sources of information (possible multiple } \\
\text { answers) }\end{array}$} & Health workers & 725 & 88.0 \\
\hline & $\begin{array}{l}\text { Radio and/or } \\
\text { Television }\end{array}$ & 184 & 22.3 \\
\hline & Friends & 225 & 27.3 \\
\hline & School & 83 & 10.1 \\
\hline \multirow[t]{4}{*}{ purpose of immunization } & To prevent disease & 736 & 89.3 \\
\hline & For healthy child & 2 & 0.2 \\
\hline & To treat sick child & 65 & 7.9 \\
\hline & Do not know & 21 & 2.6 \\
\hline \multirow[t]{6}{*}{ Numbers of vaccine-preventable disease } & Know one & 58 & 7.0 \\
\hline & know two & 52 & 6.3 \\
\hline & know three & 122 & 14.8 \\
\hline & know four & 114 & 13.8 \\
\hline & know five & 380 & 46.1 \\
\hline & I do not know & 98 & 11.9 \\
\hline \multirow[t]{2}{*}{ Knows vaccination schedule } & Yes & 803 & 97.5 \\
\hline & No & 21 & 2.5 \\
\hline \multirow[t]{4}{*}{ when the child starts their vaccination } & Just after birth & 544 & 66.0 \\
\hline & Any time & 90 & 10.9 \\
\hline & After one month & 172 & 20.9 \\
\hline & I do not know & 18 & 2.2 \\
\hline \multirow{6}{*}{$\begin{array}{l}\text { The numbers of vaccination session needed to } \\
\text { complete }\end{array}$} & Five & 455 & 55.2 \\
\hline & Four & 168 & 20.4 \\
\hline & Three & 86 & 10.4 \\
\hline & Two & 9 & 1.1 \\
\hline & One & 13 & 1.6 \\
\hline & I do not know & 93 & 11.3 \\
\hline
\end{tabular}




\begin{tabular}{|llll|} 
age of the child to complete immunization & Nine month & 797 & 96.7 \\
\cline { 2 - 3 } & Four week & 6 & 0.7 \\
\hline Ten-week & 1 & 0.1 \\
\hline 14 week & 8 & 1.0 \\
\hline I do not know & 12 & 1.5 \\
\hline
\end{tabular}

Table 6 mothers' response on Health institute service delivery on vaccination and related findings in Debre Tabor town, North West Ethiopia, $2019(n=824)$.

\begin{tabular}{|llll|}
\hline Variables & Category & Frequency & Percent (\%) \\
\hline Distances from home in munities & $<15$ & 47 & 5.7 \\
\cline { 2 - 4 } & $15-30$ & 384 & 46.6 \\
\hline Waiting time at health in munities facility & $30-60$ & 386 & 46.8 \\
\cline { 2 - 4 } & $>60$ & 7 & 0.8 \\
\cline { 2 - 4 } & $15-30$ & 310 & 37.6 \\
\cline { 2 - 4 } & $30-60$ & 113 & 48.4 \\
\cline { 2 - 4 } & $>60$ & 2 & 0.2 \\
\hline health education at health facility & Yes & 737 & 89.4 \\
\cline { 2 - 4 } & No & 87 & 10.6 \\
\hline Facility readiness & Yes & 664 & 80.6 \\
\cline { 2 - 4 } & No & 160 & 19.4 \\
\hline & Yes & 817 & 99.2 \\
\cline { 2 - 4 } & No & 7 & 0.8 \\
\hline
\end{tabular}

Table 7: Bivariable and multivariable logistic regression analysis for complete /immunization vaccination coverage by factors among children aged 12-23 months in Debre Tabor town, North West Ethiopia, 2019. $(n=824)$. 


\begin{tabular}{|c|c|c|c|c|c|c|}
\hline \multirow[t]{2}{*}{ Variables } & \multirow[t]{2}{*}{ Category } & \multicolumn{2}{|c|}{ Fully vaccinated } & \multicolumn{3}{|c|}{ Odds ratio $(95 \% \mathrm{Cl})$} \\
\hline & & Yes & No & $\begin{array}{l}\text { Crude odds } \\
\text { ratio }\end{array}$ & $\begin{array}{l}\text { Adjusted } \\
\text { odds ratio }\end{array}$ & $\begin{array}{l}\mathrm{p}- \\
\text { value }\end{array}$ \\
\hline \multirow[t]{4}{*}{$\begin{array}{l}\text { Marital status } \\
\text { of the mother }\end{array}$} & Married & $\begin{array}{l}567 \\
(82.2 \%)\end{array}$ & $\begin{array}{l}123 \\
(17.8 \%)\end{array}$ & $\begin{array}{l}3.07(1.07 \\
8.79)\end{array}$ & $\begin{array}{l}0.20 \\
(0.03,1.61)\end{array}$ & 0.130 \\
\hline & Divorced & $60(72.3 \%)$ & $23(27.7 \%)$ & $\begin{array}{l}1.74(0.56 \\
5.43)\end{array}$ & $\begin{array}{l}0.17(.02, \\
1.40)\end{array}$ & 0.099 \\
\hline & Widowed & $25(69.4 \%)$ & $11(30.6 \%)$ & $\begin{array}{l}1.52(0.43 \\
5.30)\end{array}$ & $\begin{array}{l}0.11(.01 \\
1.04)\end{array}$ & 0.055 \\
\hline & Single & $9(60 \%)$ & $6(40 \%)$ & 1 & & \\
\hline \multirow[t]{6}{*}{$\begin{array}{l}\text { Maternal } \\
\text { occupation }\end{array}$} & Housewife & $\begin{array}{l}229 \\
(76.3 \%)\end{array}$ & $71(23.7 \%)$ & 1 & & \\
\hline & Merchant & $\begin{array}{l}168 \\
(77.1 \%)\end{array}$ & $50(22.9 \%)$ & $\begin{array}{l}1.04(0.69 \\
1.57)\end{array}$ & $\begin{array}{l}0.79(0.47, \\
1.34)\end{array}$ & 0.382 \\
\hline & $\begin{array}{l}\text { Gov. } \\
\text { employed }\end{array}$ & $\begin{array}{l}237 \\
(90.5 \%)\end{array}$ & $25(9.5 \%)$ & $\begin{array}{l}2.94(1.80 \\
4.80)\end{array}$ & $\begin{array}{l}0.94(0.41, \\
2.17)\end{array}$ & 0.886 \\
\hline & Daily worker & $13(46.4 \%)$ & $15(53.6 \%)$ & $\begin{array}{l}0.27(0.12, \\
0.59)\end{array}$ & $\begin{array}{l}0.66(0.21 \\
2.09)\end{array}$ & 0.476 \\
\hline & $\begin{array}{l}\text { Non- } \\
\text { governmental } \\
\text { organization }\end{array}$ & $7(87.5 \%)$ & $1(12.5 \%)$ & $\begin{array}{l}2.17 \\
(0.26,17.94)\end{array}$ & $\begin{array}{l}1.29(0.13, \\
12.90)\end{array}$ & 0.827 \\
\hline & Others & 7 (87.5\%) & $1(12.5 \%)$ & $\begin{array}{l}2.17(0.26 \\
17.94)\end{array}$ & $\begin{array}{l}2.88(0.24 \\
35.13)\end{array}$ & 0.407 \\
\hline \multirow{4}{*}{$\begin{array}{l}\text { Educational } \\
\text { status of } \\
\text { mothers }\end{array}$} & No education & $75(70.1 \%)$ & $32(29.9 \%)$ & 1 & & \\
\hline & $\begin{array}{l}\text { Primary } \\
\text { education }\end{array}$ & $84(71.2 \%)$ & $34(28.8 \%)$ & $\begin{array}{l}1.05(0.59 \\
1.87)\end{array}$ & $\begin{array}{l}1.22(0.60 \\
2.51)\end{array}$ & 0.582 \\
\hline & $\begin{array}{l}\text { Secondary } \\
\text { education }\end{array}$ & $\begin{array}{l}200 \\
(77.5 \%)\end{array}$ & $58(22.5 \%)$ & $\begin{array}{l}1.47(0.89 \\
2.44)\end{array}$ & $\begin{array}{l}1.34(.684, \\
2.62)\end{array}$ & 0.395 \\
\hline & $\begin{array}{l}\text { More than } \\
\text { secondary }\end{array}$ & $\begin{array}{l}302 \\
(88.6 \%)\end{array}$ & 39 (11.4\%) & $\begin{array}{l}3.30(1.94 \\
5.62)\end{array}$ & $\begin{array}{l}1.98(0.84 \\
4.68)\end{array}$ & 0.118 \\
\hline \multirow[t]{2}{*}{$\begin{array}{l}\text { Planned } \\
\text { pregnancy }\end{array}$} & Yes & $\begin{array}{l}630 \\
(83.9 \%)\end{array}$ & $121(16.1 \%)$ & $\begin{array}{l}7.05(4.27 \\
11.67)\end{array}$ & $\begin{array}{l}4.08(2.20 \\
7.55)\end{array}$ & $0.000 *$ \\
\hline & No & $31(42.5 \%)$ & $42(57.5 \%)$ & 1 & & \\
\hline \multirow{2}{*}{$\begin{array}{l}\text { Antenatal } \\
\text { care (ANC) } \\
\text { follow up }\end{array}$} & Yes & $\begin{array}{l}660 \\
(80.8 \%)\end{array}$ & $\begin{array}{l}157 \\
(19.2 \%)\end{array}$ & $\begin{array}{l}25(3.02 \\
211.01)\end{array}$ & $\begin{array}{l}4.03(.05 \\
31.15)\end{array}$ & 0.535 \\
\hline & No & $1(14.3 \%)$ & $6(85.7 \%)$ & 1 & & \\
\hline $\begin{array}{l}\text { Postnatal } \\
\text { care follow }\end{array}$ & Yes & $283(88.4 \%)$ & $37(11.6 \%)$ & $\begin{array}{l}2.55(1.71, \\
3.79)\end{array}$ & $\begin{array}{l}1.40(0.87, \\
2.23)\end{array}$ & 0.162 \\
\hline
\end{tabular}




\begin{tabular}{|c|c|c|c|c|c|c|}
\hline up & No & $378(75.0 \%$ & $126(25.0 \%)$ & 1 & & \\
\hline \multirow{2}{*}{$\begin{array}{l}\text { Mother } \\
\text { vaccinated } \\
\text { for tetanus } \\
\text { toxoid }\end{array}$} & Yes & $\begin{array}{l}658 \\
(80.9 \%)\end{array}$ & $\begin{array}{l}155 \\
(19.1 \% 0\end{array}$ & $\begin{array}{l}11.32(2.97 \\
43.16)\end{array}$ & $\begin{array}{l}0.87(0.04 \\
21.41)\end{array}$ & 0.929 \\
\hline & No & 3 (27.3\%) & 8 (72.7\%) & 1 & & \\
\hline \multirow[t]{2}{*}{ Place of birth } & $\begin{array}{l}\text { Health } \\
\text { institute }\end{array}$ & $\begin{array}{l}651 \\
(81.8 \%)\end{array}$ & $\begin{array}{l}145 \\
(18.2 \%)\end{array}$ & $\begin{array}{l}8.08(3.65 \\
17.87)\end{array}$ & $\begin{array}{l}6.29(2.21 \\
17.96)\end{array}$ & $0.001 *$ \\
\hline & Home & $10(35.7 \%)$ & $18(64.3 \%)$ & 1 & & \\
\hline \multirow[t]{4}{*}{ Birth order } & First & $\begin{array}{l}320 \\
(81.6 \%)\end{array}$ & 72 (18.4\%) & $\begin{array}{l}2.03(1.07 \\
3.87)\end{array}$ & $\begin{array}{l}1.22(0.56 \\
2.67)\end{array}$ & 0.615 \\
\hline & Second & $\begin{array}{l}213 \\
(82.2 \%)\end{array}$ & $46(17.8 \%)$ & $\begin{array}{l}2.12(1.08, \\
4.14)\end{array}$ & $\begin{array}{l}1.12(0.51, \\
2.49)\end{array}$ & 0.774 \\
\hline & Third & $93(76.2 \%)$ & $29(23.8 \%)$ & $\begin{array}{l}1.47(0.71 \\
3.02)\end{array}$ & $\begin{array}{l}1.10(0.47, \\
2.58)\end{array}$ & 0.819 \\
\hline & $\begin{array}{l}\text { Fourth \& } \\
\text { above }\end{array}$ & 35 (68.6\%) & 16 (31.7\%) & 1 & & \\
\hline \multirow{2}{*}{$\begin{array}{l}\text { Health } \\
\text { education at } \\
\text { the health } \\
\text { institution }\end{array}$} & Yes & $\begin{array}{l}616 \\
(83.6 \%)\end{array}$ & $\begin{array}{l}121 \\
(16.4 \%)\end{array}$ & $\begin{array}{l}4.75(2.99 \\
7.55)\end{array}$ & $\begin{array}{l}1.81(0.99, \\
3.32)\end{array}$ & 0.054 \\
\hline & No & $45(51.7 \%)$ & 42 (48.3\%) & 1 & & \\
\hline \multirow{2}{*}{$\begin{array}{l}\text { Home visit by } \\
\text { health } \\
\text { workers }\end{array}$} & Yes & $\begin{array}{l}574 \\
(86.4 \%)\end{array}$ & 90 (13.6\%) & $\begin{array}{l}5.35(3.65 \\
7.84)\end{array}$ & $\begin{array}{l}3.37(2.13 \\
5.33)\end{array}$ & $0.000 *$ \\
\hline & No & 87 (54.4\%) & 73 (45.6\%) & 1 & & \\
\hline \multirow[t]{2}{*}{$\begin{array}{l}\text { Knowledge of } \\
\text { mothers }\end{array}$} & $\begin{array}{l}\text { Good } \\
\text { knowledge }\end{array}$ & $\begin{array}{l}410 \\
(91.3 \%)\end{array}$ & 39 (8.7\%) & $\begin{array}{l}5.19(3.51, \\
7.70)\end{array}$ & $\begin{array}{l}3.48(2.25 \\
5.38)\end{array}$ & $0.000 *$ \\
\hline & $\begin{array}{l}\text { Poor } \\
\text { knowledge }\end{array}$ & $\begin{array}{l}251 \\
(66.9 \%)\end{array}$ & $\begin{array}{l}124 \\
(33.1 \%)\end{array}$ & 1 & & \\
\hline
\end{tabular}

$1=$ Reference group

Note: * significantly associated at " $p \leq 0.001 "$.

\section{Figures}




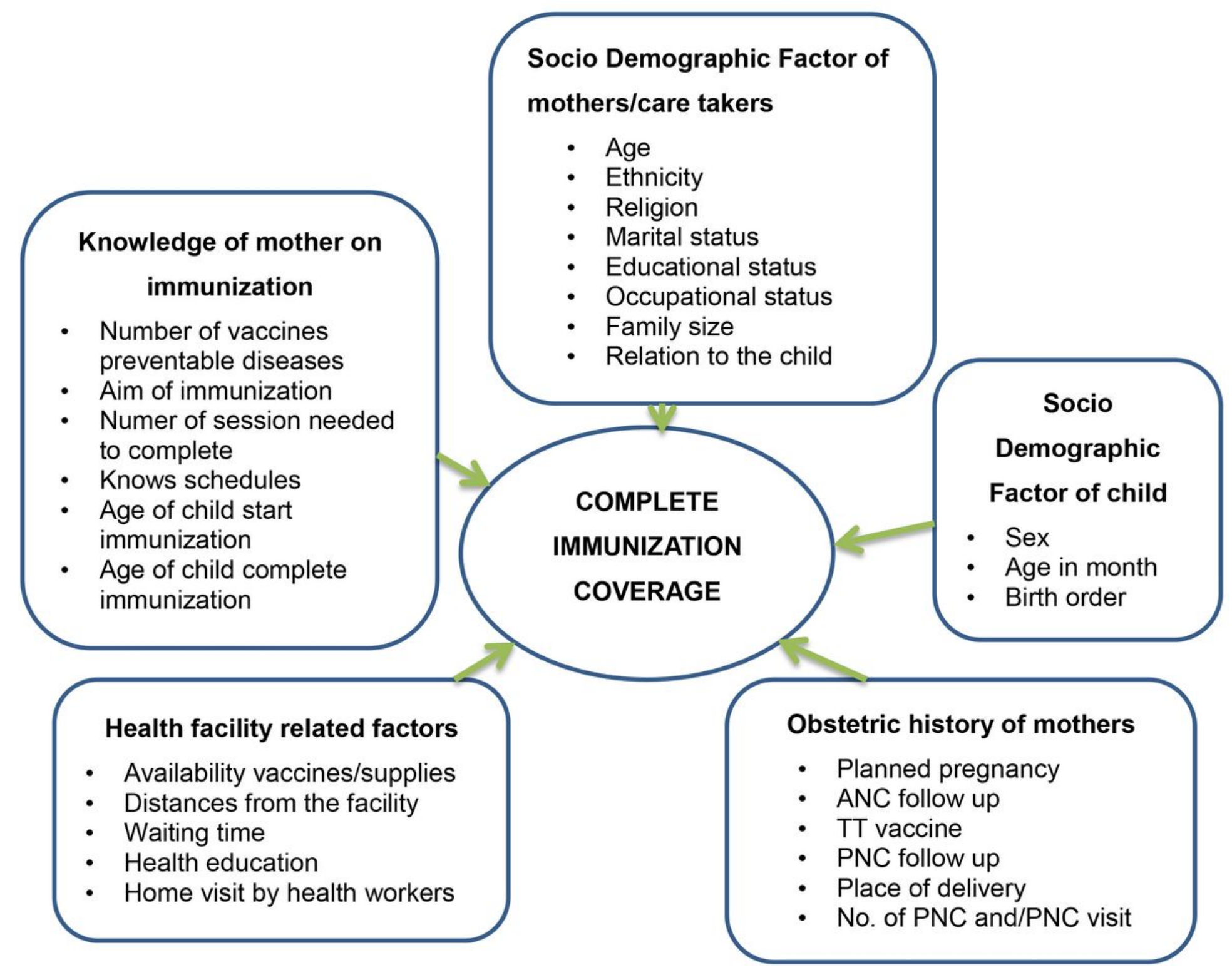

Figure 1

Conceptual framework for complete vaccination/immunization coverage and associated factors among mothers and children aged 12-23 months pair in Debre Tabor Town, Northwest, Ethiopia, 2019 


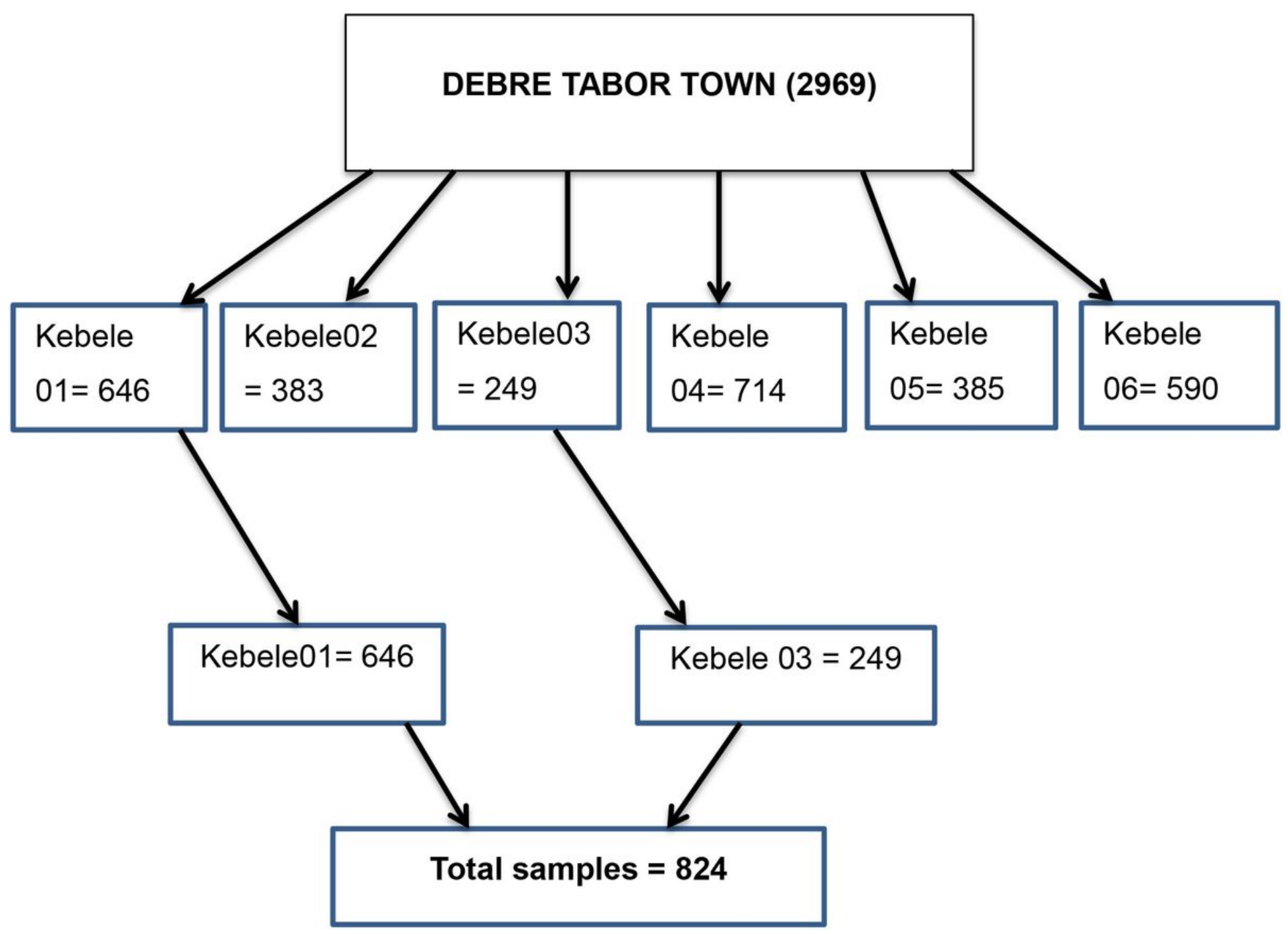

Figure 2

Schematic presentation of the sampling procedure for complete vaccination/immunization coverage and its associated factors among mothers and children aged 12-23 months' pair at Debre Tabor town south Gondar Zone, North-west Ethiopia, 2019. 